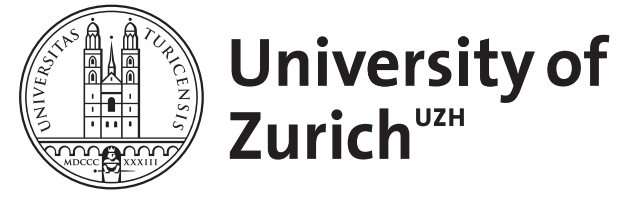
Archive

University of Zurich

University Library

Strickhofstrasse 39

CH-8057 Zurich

www.zora.uzh.ch

Year: 2007

\title{
Your diagnosis? Umbilical cord tumor
}

Natalucci, Giancarlo ; Wisser, Josef ; Weil, Robert ; Stallmach, Thomas ; Ulrich Bucher, Hans

DOI: https://doi.org/10.1007/s00431-006-0301-2

Posted at the Zurich Open Repository and Archive, University of Zurich

ZORA URL: https://doi.org/10.5167/uzh-155912

Journal Article

Published Version

Originally published at:

Natalucci, Giancarlo; Wisser, Josef; Weil, Robert; Stallmach, Thomas; Ulrich Bucher, Hans (2007). Your diagnosis? Umbilical cord tumor. European Journal of Pediatrics, 166(7):753-756.

DOI: https://doi.org/10.1007/s00431-006-0301-2 


\title{
Your diagnosis? Umbilical cord tumor
}

\author{
Giancarlo Natalucci • Josef Wisser • Robert Weil • \\ Thomas Stallmach • Hans Ulrich Bucher
}

Received: 23 May 2006 / Accepted: 29 August 2006 / Published online: 17 November 2006

(C) Springer-Verlag 2006

\section{Clinical information}

A 35-year-old woman, gravida 3, para 3, at $331 / 7$ weeks of gestation was referred to the obstetric clinic for prenatal assessment of an echogenic mass of the umbilical cord detected during a routine ultrasound examination. Chorionic villus biopsy for advanced maternal age at 13-week gestation revealed a normal $46 \mathrm{XX}$ karyotype. Sonographic assessment of the fetus demonstrated growth parameters appropriate for the gestational age. The abdominal wall was

G. Natalucci $(\bowtie) \cdot H$. Ulrich Bucher

Clinic of Neonatology, University Hospital,

Frauenklinikstrasse 10,

8091 Zürich, Switzerland

e-mail: Giancarlo.Natalucci@kispi.unizh.ch

J. Wisser

Department of Obstetrics and Gynaecology, University Hospital,

Zurich, Switzerland

R. Weil

Clinic of Surgery, Children's Hospital,

Zurich, Switzerland

T. Stallmach

Institute of Pathology, University Hospital,

Zurich, Switzerland closed, with an inhomogeneous mass measuring $43 \times 32 \times$ $28 \mathrm{~mm}$ near the insertion of the umbilical cord (Fig. 1). The cardiotocogram showed no fetal distress. Doppler flow studies of the umbilical cord showed three vessels, displaced by a multilobulated echogenic tumor. Maternal serum screening showed an elevated level of alphafetoprotein $(326 \mu \mathrm{g} / \mathrm{l})$, but no signs of congenital infection.

At $385 / 7$ weeks of gestation, a girl was delivered vaginally, weighing $2,840 \mathrm{~g}$ (10th-25th centile), with a length of $47 \mathrm{~cm}$ (10th-25th centile) and head circumference of $33 \mathrm{~cm}$ (10th-25th centile). She adapted with Apgar scores of $8 / 9 / 9$, and the arterial cord $\mathrm{pH}$ was 7.31 . The umbilical cord showed a nodular bulge proximal to its insertion into the abdominal wall. It measured $4 \mathrm{~cm}$ in diameter, had a smooth, translucent, pearly colored surface, without superficial vessels or pulsations, and was of firm, elastic consistency. A blue core was discernible within (Fig. 2). The findings were associated with marked thickening and edema of the Wharton's jelly, and one vein and two arteries were present within the cord. A 1-cm segment of normal umbilical cord separated the tumor from the intact abdominal wall. Abdominal ultrasound examination showed no visceral abnormalities. The umbilical cord was clamped distal to the lesion, and the infant recovered in a puerperal care unit. The macro- and microscopic placenta examination $(387 \mathrm{~g}, 19 \times 15 \times 3 \mathrm{~cm})$ revealed no abnormalities. At 2 days of age, the infant was transferred to a pediatric surgery unit for surgical revision. 
Fig. 1 Fetal abdominal wall with umbilicus at $33+1$ weeks of gestation. The arrow marks the umbilical vein passing through the abdominal wall. The dimensions of the umbilical cord tumor are shown

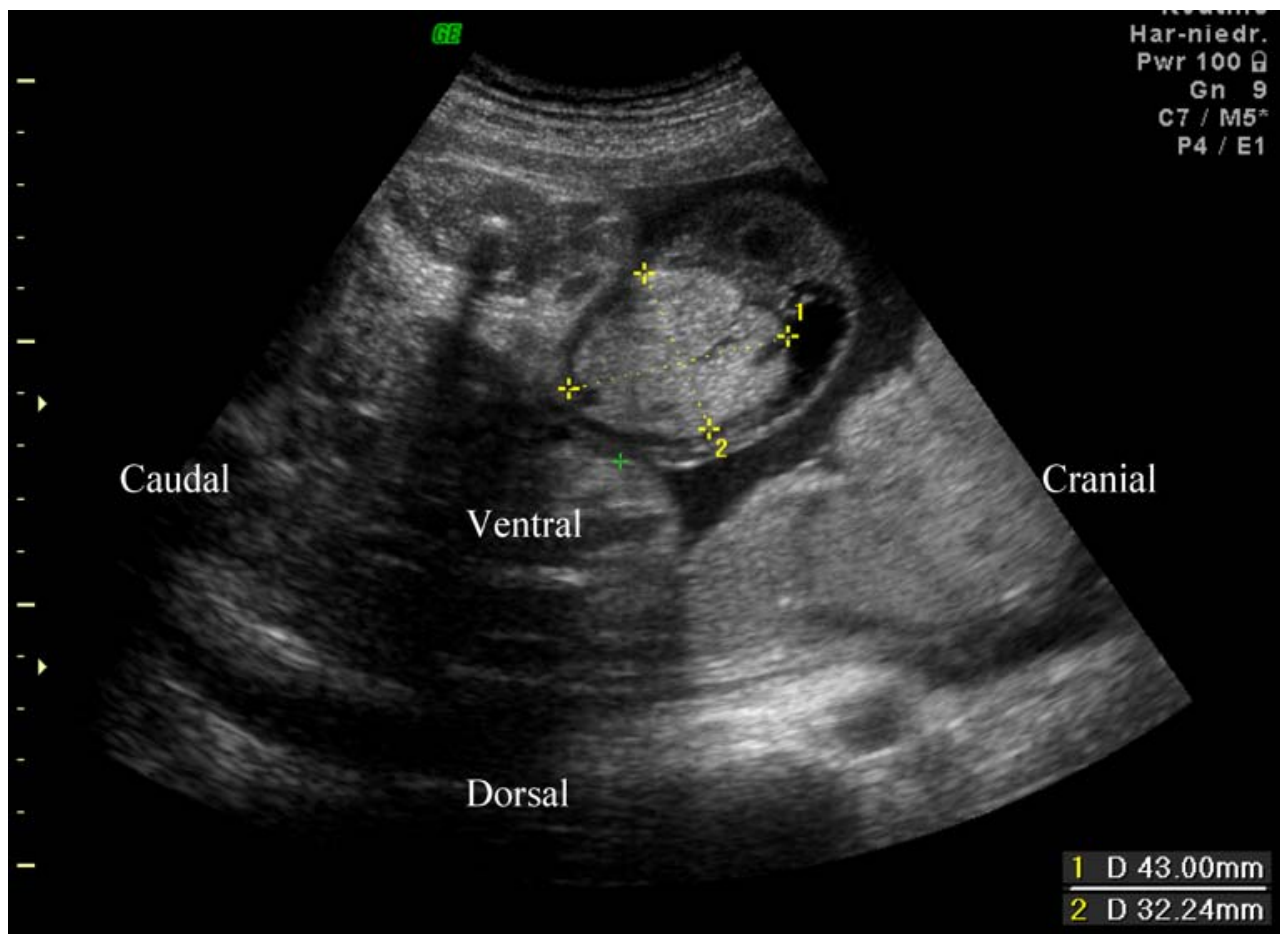

the Wharton's jelly was mostly replaced by abundant aggregates of thin-walled capillaries. The capillary hemangioma showed a diffuse growth around the vessels, with focal dissection of the muscular coat of the umbilical vein. In addition, nodular aggregates were seen, some freshly thrombosed (Fig. 3). Distal to the removed lesion, the remaining umbilical cord was unremarkable.

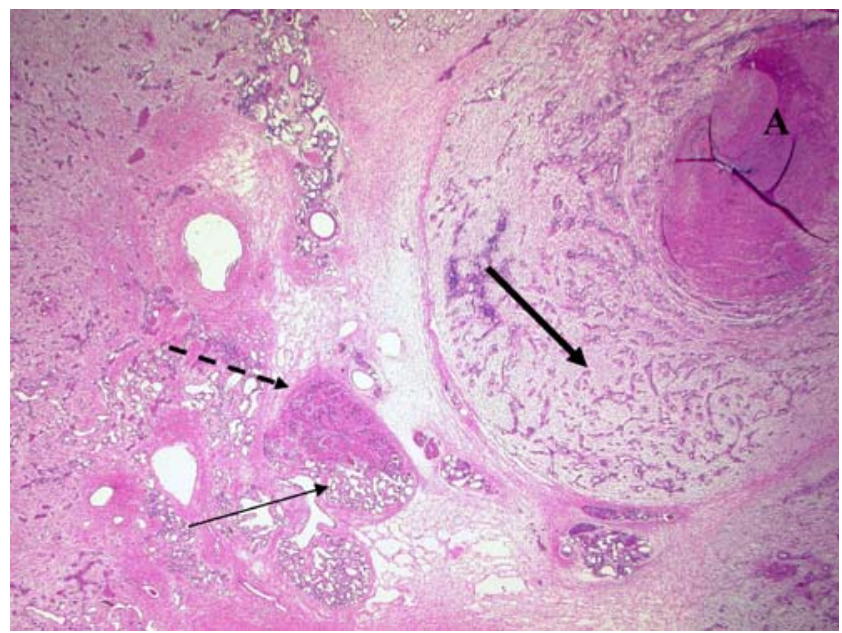

Fig. 3 Cross-section of umbilical cord showing an umbilical artery (a). Note the abundance of tiny capillaries around the artery (thick arrow). Some capillary growth is nodular (thin arrow) with occasional fresh thromboses (dotted arrow). Most of the Wharton's jelly is replaced by capillaries. Hematoxylin-eosin, magnification $\times 100$ 
Table 1 Differential diagnosis of an umbilical cord tumor

\begin{tabular}{|c|c|c|}
\hline Diagnosis & Macroscopic aspect & Association with other findings \\
\hline $\begin{array}{l}\text { 1) Umbilical cord } \\
\text { teratoma }\end{array}$ & $\begin{array}{l}\text { Nodular or cystic; maximum } 10 \mathrm{~cm} \mathrm{Ø;} \mathrm{normal} \mathrm{umbilical} \\
\text { cord origin; all along the umbilical cord }\end{array}$ & - $50 \%$ associated with other malformations \\
\hline $\begin{array}{l}\text { 2) Hemangioma of the } \\
\text { umbilical cord }\end{array}$ & $\begin{array}{l}\text { Nodular } 0.2 \text { to } 18 \mathrm{~cm} \varnothing \text {; normal umbilical cord origin; } \\
\text { proximal to the placenta }\end{array}$ & $\begin{array}{l}\text { - Mostly isolated finding; } \bullet \text { edema of Wharton's jelly; } \\
\text { - complication: intrauterine bleeding }\end{array}$ \\
\hline 3.1) Hernia into the cord & $\begin{array}{l}\text { Nodular }<4 \mathrm{~cm} \varnothing \text {; normal umbilical cord origin; } \\
\text { proximal to the abdomen; elastic consistence }\end{array}$ & $\begin{array}{l}\bullet \text { Mostly isolated finding; } \bullet \text { associated with Meckel's } \\
\text { diverticulum }\end{array}$ \\
\hline 3.2) Omphalocele & $\begin{array}{l}\text { Abdominal organ prolapse }>4 \mathrm{~cm} \varnothing ; \text {; large umbilical cord } \\
\text { origin }\end{array}$ & $\begin{array}{l}\text { - Associated with other malformations, syndromes or } \\
\text { chromosomal abnormalities }\end{array}$ \\
\hline 4) Umbilical cord cyst & $\begin{array}{l}\text { Nodular or cystic; most often single; normal umbilical } \\
\text { cord origin; all along the umbilical cord }\end{array}$ & - Mostly isolated finding \\
\hline 5) Umbilical cord polyp & $\begin{array}{l}\text { Nodular, solid, reddish, exudative, sometimes ulcerated } \\
\text { and bleeding }\end{array}$ & - Meckel's diverticulum and umbilical enteric fistula \\
\hline $\begin{array}{l}\text { 6) Umbilical cord } \\
\text { hematoma }^{1} \text { and } \\
\text { aneurysm }^{2}\end{array}$ & $\begin{array}{l}{ }^{1} \text { Nodular, livid; }{ }^{2} \text { cystic in US, turbulent, non-pulsatile } \\
\text { blood flow }\end{array}$ & $\begin{array}{l}\bullet{ }^{1} \text { Fetal distress; } \bullet{ }^{2} \text { trisomy } 18 \text {, single umbilical } \\
\text { artery, arteriovenous fistula }\end{array}$ \\
\hline
\end{tabular}

\section{Discussion}

Differenial diagnosis of an umbilical cord tumor

Nodular bulges of the umbilical cord are rare entities of polymorphous presentation that can be detected prenatally by ultrasound examination. Their differential diagnosis and some of the respective characteristics are listed in Table 1, a more detailed review of which is beyond the this report's scope. The clinical significance common to all of these anomalies is determined by their size, which can potentially cause vascular compromise and affect fetal growth. After birth, umbilical cord clamping should be distal to the lesion to avoid intestinal strangulation. An ultrasound investigation of the lesion is recommended, and referral of the newborn to a pediatric surgery clinic for revision and correction is mandatory, but not an emergency.

\section{Umbilical cord teratoma}

Umbilical cord teratoma is a polymorphous, congenital nodular-cystic neoplasm having different cellular and organoid components deriving from more than one germ layer. Its texture varies from soft adipous areas to firm/solid cartilaginous or bony structures characterized by distinct calcification. Teratomas are observed all along the umbilical cord, the origin of which is of normal aspect. Usually considered benign, about one half of all reported cases are associated with other malformations [10].

\section{Hemangioma of the umbilical cord}

Hemangioma of the umbilical cord is characterized by welldefined aggregates of closely packed, thin-walled capillary proliferation originating from the umbilical arteries, the umbilical vein or vitelline capillaries [7]. The etiology is still not clear; it may represent a true neoplasm or it may be a developmental abnormality (hamartoma). Even though it lacks circumscription or encapsulation, it never metastasizes [3], although it has been reported to be associated with additional skin, liver, intra-abdominal and placental hemangiomas. Most often hemangioma is an isolated anomaly, but large lesions have been described in association with polyhydramnios [2], intrauterine growth retardation, elevated maternal serum alpha-fetoprotein [9] and fetal malformations [2]. Some authors have also reported its association with premature delivery and even with fetal death caused by impaired umbilical circulation resulting in nonimmune hydrops fetalis [4], torsion, compression, or stenosis of the umbilical vessels, fetal hemorrhage [7], thrombosis of an umbilical vessel and hematoma of the umbilical cord [11]. We reviewed 37 reports in the literature from 1951 through 2005, in most of which the lesion was referred to as hemangioma, and rarely as angiomyxoma, myangioma or hemangiofibromyxoma because of the myxoid appearance of the commonly associated edematous degeneration of the Wharton's jelly. A possible hereditary predisposition to this vascular anomaly is still under discussion.

\section{Hernia into the cord}

Hernia into the cord is a rare, peculiar form of abdominal wall defect differing from the omphalocele by its smaller size and its structure, consisting in a protruding peritoneal segment in the umbilical cord containing no intestinal loop. It develops proximally to the fetal abdominal wall and, typically, the origin of the umbilical cord is of normal size (diameter about $1 \mathrm{~cm}$ ) and aspect. In the majority of cases it is an isolated finding. 


\section{Omphalocele}

Omphalocele is the most frequent pathologic entity of those cited above, with an estimated incidence of 1 in 3,000 to 4,000 births. It is a form of abdominal wall defect that is, by definition, between 4 and $12 \mathrm{~cm}$ in diameter. It consists of a protrusion of intestinal loops into the base of the umbilical cord, occasionally accompanied by other visceral organs such as the liver, covered by peritoneum without overlying skin. Characteristically, the origin of the umbilical cord is abnormally large. In the majority of cases, omphalocele is associated with other congenital anomalies of the gastrointestinal tract or cardiovascular system, syndromes or chromosomal aberrations.

\section{Cystic lesions}

Cystic lesions originate from embryonic vestiges remaining as a consequence of the incomplete obliteration of the urachus and omphalomesenteric duct. They are more often single than multiple findings and are usually isolated, even though their association with other congenital anomalies, usually of the gastrointestinal tract, and other syndromes and sequences has been described. The presence of multiple umbilical cord cysts is associated with an increased risk of miscarriage, aneuploidy and congenital anomalies [5]. Additionally, pseudocysts have also been described, originating as a result of myxoid degeneration of the Wharton's jelly secondary to persistent patent urachus, urachus cysts or abdominal wall defects [1].

\section{Umbilical cord polyp}

Umbilical cord polyp results from the persistence of protruding intestinal tissue within the umbilical cord, remnants of the omphalomesenteric duct, which differentiates into proliferating gastrointestinal cells. Communication with the intestinal canal is not always lost. As an isolated finding, it can be a harmless lesion, but its presence should lead to a careful investigation of the possible presence of other omphalomesenteric duct anomalies, such as Meckel's diverticulum and umbilical enteric fistula. The lesion can be exudative and complicated by ulceration and bleeding [6]. There is a report in the literature of an umbilical cord polyp originating from the urachus [8].

\section{Hematoma and aneurysm of the umbilical cord}

Hematoma of the umbilical cord is usually an accidental event secondary to cordocentesis done for diagnostic purposes, while spontaneous hematoma remains very rare $[11,12]$. Umbilical artery aneurysm is an extremely rare vascular anomaly associated with poor fetal outcome, comprehending chromosomal aberration, progressive oligohydramnios and fetal death due to acute umbilical venous compression [13].

\section{Conclusion}

We report the case of an infant with an umbilical cord tumor that had twice been diagnosed previously: antenatally, by ultrasound, as a teratoma, based on its inhomogeneous character and the absence of an intratumoral flow, and postnatally as a hernia into the cord. The infant was born at term weighing $2,840 \mathrm{~g}$, with a 4-cm diameter nodular bulge in the umbilical cord. The definitive diagnosis was made by histopathology as hemangioma of the umbilical cord.

\section{References}

1. Antonelli E, Wildhaber BE, Pfister RE (2005) Giant umbilical cord. In: Case of the Month: January 2005. Swiss Society of Neonatology. http://www.neonet.ch

2. Armes JE, Billson VR (1994) Umbilical cord hemangioma associated with polyhydramnios, congenital abnormalities and perinatal death in a twin pregnancy. Pathology 26:218-220

3. Caldarella A, Buccoliero AM, Taddei A, Savino L, Taddei GL (2003) Hemangioma of the umbilical cord: report of case. Pathol Res Pract 199:51-55

4. Carles D, Maugey-Laulom B, Roux D, Jimenez M, Saudubray F, Alberti EM (1994) Lethal hydrops fetalis secondary to an umbilical cord hemangioma. Ann Pathol 14:244-247

5. Grezzi F, Raio L, Di Naro E, Franci M, Cromi A, Durig P (2003) Single and multiple umbilical cord cysts in early gestation: two different entities. Ultrasound Obstet Gynecol 21:215-219

6. Guschmann M, Janda J, Wenzelides K, Vogel M (2002) Intestinal polyp of the umbilical cord. Zentralbl Gynakol 124:132-134

7. Heifetz SA, Rueda-Pedraza ME (1983) Hemangiomas of the umbilical cord. Pediatr Pathol 1:385-398

8. Oguzkurt P, Kotiloglu E, Tanyel FC, Hicsonmez A (1996) Umbilical polyp originating from urachal remnants. Turk J Pediatr 38:371-374

9. Resta RG, Luthy DA, Mahony BS (1988) Umbilical cord hemangioma associated with extremely high alpha-fetoprotein levels. Obstet Gynecol 72:488-491

10. Satgé DCL, Laumond M-A, Desfarges F, Chenard M-P (2001) An umbilical cord teratoma in a 17 -week-old fetus. Prenat Diagn 21:284-288

11. Schlaeder G, Irrmann M, Philippe E (1964) A case of hemangioma of the cord with hematoma. Bull Fed Soc Gynecol Obstet Lang Fr 16:208-210

12. Seoud M, Aboul-Hosn L, Nassar A, Khalil A, Usta I (2001) Spontaneous umbilical cord hematoma: a rare cause of acute fetal distress. Am J Perinatol 18:99-102

13. Sepulveda W, Corral E, Kottmann C, Illanes S, Vasquez P, Monckeberg MJ (2003) Umbilical artery aneurysm: prenatal identification in three fetuses with trisomy 18. Ultrasound Obstet Gynecol 21:292-296 